\title{
Myocardial phenotypes and dysfunction in HFpEF and HFrEF assessed by echocardiography and cardiac magnetic resonance
}

\author{
Bostjan Berlot $^{1,2}$ (1) $\cdot$ Chiara Bucciarelli-Ducci $^{2} \cdot$ Alberto Palazzuoli $^{3} \cdot$ Paolo Marino $^{4}$
}

Published online: 14 November 2019

(C) The Author(s) 2019

\begin{abstract}
Heart failure (HF) with either reduced or preserved ejection fraction is an increasingly prevalent condition. Cardiac imaging plays a central role in trying to identify the underlying cause of the underlying systolic and diastolic dysfunction, as the imaging findings have implications for patient's management and individualised treatment. The imaging modalities used more frequently in patients with heart failure in clinical routine are echocardiography and cardiac magnetic resonance. Both techniques keep some strengths and weakness due to their spatia

1 and temporal resolution. Notably, several features in the diagnostic algorithm of heart failure with preserved systolic function (HFpEF) may be improved by an integrated approach. This review focuses on the role of each modality in characterising cardiac anatomy, systolic and diastolic function as well as myocardial tissue characterisation in the most common phenotypes of dilated and hypertrophied hearts.
\end{abstract}

Keywords Echocardiography $\cdot$ Cardiac magnetic resonance imaging $\cdot$ Ischemic and non-ischemic heart failure $\cdot$ Systolic and diastolic dysfunction

Cardiac imaging plays a central role in trying to phenotype the underlying cause of heart failure (HF) which has implications for patient's management and individualised treatment. Heart failure has recently been classified as heart failure with reduced ejection fraction (HFrEF) or preserved ejection fraction (HFpEF) [1]; although, it is still debated whether these are two different entities or just a different stage of same ongoing process $[2,3]$. The clinical imaging modalities available to investigate patients with heart failure are echocardiography, nuclear cardiology techniques, computed tomography and cardiac magnetic resonance (CMR). In this paper, we review

Chiara Bucciarelli-Ducci

c.bucciarelli-ducci@bristol.ac.uk

1 Department of Cardiology, University Medical Centre Ljubljana, Zaloska cesta 7, 1000 Ljubljana, Slovenia

2 Bristol Heart Institute, Bristol National Institute of Health Research (NIHR) Biomedical Research Centre, University Hospitals Bristol NHS Trust and University of Bristol, Bristol, UK

3 Cardiovascular Diseases Unit Department of Internal Medicine, Le Scotte Hospital University of Siena Italy, Siena, Italy

4 Department of Translational Medicine, Eastern Piedmont University, Via Solaroli 17, Novara, Italy the role of echocardiography and CMR in patients with HFrEF and HFpEF.

Two-dimensional transthoracic echocardiography is the first line imaging tool providing information on function, cavity size, relative wall thickness (RWT) and myocardial mass which are used for classification of typical geometric phenotypes - concentric or eccentric hypertrophy and remodelling $[4,5]$. Moreover, echocardiography deformation imaging can discriminate between active myocardial segmental deformation and passive displacement of a dysfunctional myocardial segment due to adjacent segment tethering and global cardiac motion. However, echocardiography alone cannot identify interstitial infiltration and intracellular accumulation of metabolic substrates [6].

Cardiac magnetic resonance (CMR) is the gold standard for cardiac anatomical and functional quantification, with unique capabilities of non-invasive tissue characterisation [7-9], complementing well echocardiography. Cine imaging covering the LV in short axis from apex to base is used for measuring left ventricular (LV) volumes, ejection fraction (EF) and regional function. The 3D dataset is not affected by geometric assumptions and therefore less prone to error compared with two-dimensional (2D) echocardiography particularly in remodelled ventricles [10]. Non-invasive tissue characterisation by CMR can be achieved with $\mathrm{T} 2$ imaging and $\mathrm{T} 1$ 
imaging post-contrast injection. The latter technique, called late gadolinium enhancement (LGE), relies on gadoliniumbased contrast agents temporarily accumulating in regions of increased extracellular space (due to myocardial scar, necrosis, fibrosis, infiltration), following the underlying pathophysiological process, and creating typical LGE patterns [11] that guide the diagnosis.

Novel CMR tissue characterisation techniques are called CMR relaxometry (T1 and T2 mapping and extracellular volume fraction (ECV)) which allow a more detailed and quantitative approach to tissue characterisation and 4D-Flow which provides quantitative information on intracavitary flows. Current applications appear particularly useful for diastolic dysfunction detection although they deserve a specific comparison with traditional Doppler and Tissue Doppler analysis in order to confirm the applicability in clinical practice.

The most common cardiomyopathic processes underpinning HFpEF (hypertrophied phenotypes) and HFrEF (dilated phenotypes) are discussed below.

\section{Left ventricular hypertrophic phenotypes}

Left ventricular (LV) hypertrophy (LVH) is a consequence of an underlying genetic or acquired condition and it is accompanied by alterations in cardiac function and haemodynamics. The differential diagnosis between LVH due to physiological adaptation or underlying pathology can be challenging.

Non-physiological left ventricular hypertrophy (LVH) regardless to the underlying cause leads to important cardiovascular complications such as atrial fibrillation, diastolic and systolic heart failure [12], and it is associated with increased risk for all-cause morbidity and mortality [13].

\section{Hypertensive heart disease}

Systemic blood pressure elevation is the most common cause of the increment in ventricular mass with a high RWT, which results in concentric or eccentric hypertrophy and concentric remodelling [14]. These structural changes provide a mechanism for maintenance of normal LV systolic wall stress in the presence of a high systolic pressure, although up to $60 \%$ of the variance of LV mass may be due to genetic factors independent of blood pressure [15]. The earliest change appears to be an increase in RWT before there is a detectable increase in LV mass [16]. In hypertensive heart disease (HHD), the wall thickening is influenced by ethnicity, neurohumoral factors and genetic variants, is commonly symmetrical and in basal segments rarely exceeding $15 \mathrm{~mm}$ [17]. However, locally increased wall stress in the basal septum can result in regionally increased wall thickness - also known as septal bulging, mimicking other asymmetric hypertrophic phenotypes. Clinical heart failure in hypertensive heart disease can occur either in the setting of reduced or preserved LVEF [18]. Echocardiography is the first line diagnostic tool. However, traditional parameters offer little clue about the underlying aetiology, hence novel applications are gaining in popularity. Despite that cardiac hypertrophy may be analysed with the two methods, there is an existing gap in LV hypertrophy and mass measurement between the two techniques: indeed LV mass is currently calculated with standardised formulas in a parasternal longitudinal view axis in echo by the assumption that LV has an ellipsoid shape [19]. Conversely, LV mass in CMR is measured in a transversal view by the sum of the whole myocardial slices from basal to apical level [20]. This make CMR much more reproducible without geometric assumption and lower cut-off value compared with echo. This is an important item when physicians calculate the global CV risk in hypertensive or high-risk subjects.

Global longitudinal strain (GLS) is an emerging parameter currently available with both methods. GLS is typically reduced in advanced stages of HHD, and it is strongly associated with diastolic dysfunction, it is less dependent on afterload changes and degree of LVH compared with EF, and it has a role in differentiating HHD from other hypertrophic phenotypes [21, 22]. CMR is superior to echocardiography due to its possibility of tissue characterisation. By magnetic resonance study, it is possible to ascertain the burden of myocardial fibrosis, extracellular collagen deposition extension and site. Therefore, the absence of LGE on CMR increases the predictive power in diagnosing HHD over and above geometrical and morphological features [23, 24]. Finally, HHD is normally accompanied with structural or functional changes in arteries or end organs (heart, blood vessels, brain, eyes and kidney) as a consequence of long lasting hypertension even in asymptomatic patients [25]. Evidence of increased blood pressure is the clinical hallmark of the disease, even though approximately $15 \%$ of patients might present with a normal office BP (masked hypertension) [26]. The most common functional feature of HHD, apart structural LVH and remodelling, is the alteration of left filling pressure due to both increased LV mass and stiffness associated with reduced elastic properties of myocardial tissue. Notably, echocardiography and Doppler application due to its high temporal resolution, offers a suitable and practical tool to recognise LV diastolic filling dysfunction by the combined analysis of trans-mitral pulsed waves Doppler and myocardial tissue Doppler (TDI). Therefore, additional study of pulmonary vein flow allows to a characterisation of diastolic degree and haemodynamic conditions into the left cardiac chamber $[27,28]$. A similar analysis have recently been reproduced during CMR examination in a phase-contrast acquisition measuring trans-mitral and venous flow velocities in a post-processing analysis including around 40 cardiac phases of the whole cardiac cycle. Additional analysis comprises myocardial tagging that calculates radial and circumferential motion 
during cardiac relaxation, and more recently, feature tracking to detect myocardial strain [29].

\section{LV hypertrophy in cardiac amyloidosis}

Infiltrative myocardial disease particularly cardiac amyloidosis can present with very heterogenous hypertrophic phenotypes with wide ranges of wall thicknesses including normal [30]. Granular appearance on echocardiography, biventricular hypertrophy with involvement of the right ventricular free wall, increased thickness of the atrio-ventricular valves, thickening of the interatrial septum and the presence of a small pericardial effusion usually trigger a suspicion [30]. Whereas the light chain amyloidosis (AL) normally follows concentric symmetric hypertrophic pattern, the transthyretin amyloidosis (TTR) is typically asymmetrical [31]. Thickened myocardium and conventional echo parameters have low accuracy for the diagnosis of cardiac amyloidosis, which is mostly due to their low sensitivity [32]. However, some echo indices, enlarged left atrial volume index, reduced LV diameters and volumes, global parietal thickness and increased parietal backscatter have higher specificity and have a potential to be used to 'rule in' potential amyloidosis cases [33,34], suggesting diastolic dysfunction as a leading functional abnormality in this population. A typical restrictive filling Doppler pattern is characterised by a high early wave with shortened deceleration time and isovolumetric time. Conversely, the atrial contribution is reduced and often blunted even in those patients without atrial fibrillation. Pulmonary flow analysis demonstrates increased atrial reverse wave associated with both reduced systolic and diastolic waves [35]. The alteration of intrinsic myocardial relaxation forces is demonstrated by significative lowering of tissue $e^{\prime}$ velocity associated with increased $E / e^{\prime}$ ratio. Myocardial deformation parameters or patterns of regional strain values such as relative apical sparing or septal apical-base longitudinal strain gradient may have a better differentiating capacity in detecting and differentiating cardiac amyloidosis from other hypertrophic substrates, including HCM, hypertrophy in aortic stenosis or metabolic cardiomyopathies [36]. Using deformation imaging, LV dysfunction can be detected prior to any signs of morphological or functional impairment as assessed by $2 \mathrm{D}$ echocardiography or assessment of diastolic function [34]. However, all aforementioned conditions may present with regional impairment patterns that closely resemble cardiac amyloidosis. CMR is superior to echocardiography and plays an important role in diagnosis of cardiac amyloidosis due to peculiar myocardial and blood-pool gadolinium kinetics in this disease. Detection of transmural or subendocardial LGE with suboptimal myocardial nulling caused by similar myocardial and blood T1 signals, is unusual but highly specific pattern in amyloidosis. Furthermore, native T1 mapping values and ECV are severely increased in amyloidosis [37]. These novel CMR parameters are more sensitive for detecting early disease than LGE imaging, correlate better with markers of systolic and diastolic dysfunction and have a potential to give information on cardiac amyloid load without usage of contrast agents [38].

\section{Left ventricular dilated phenotypes}

Dilated phenotypes are a heterogenous group characterised by large LV cavities with eccentric remodelling or hypertrophy and impaired contractility. Such phenotypes can be a response to abnormal loading conditions typically in valvular disease or hypertension, severe coronary or congenital disease [39] or predominantly confined to heart muscle like in inherited or acquired cardiomyopathies. Transthoracic echocardiography is used as a first line imaging tool for identifying and description of the phenotype. It typically shows global left or biventricular hypokinesis with or without regional wall motion abnormalities. Ventricular and atrial dilatation, intracardiac thrombi and functional mitral regurgitation due to annular dilatation might also be noted. Doppler parameters can assist in quantifying valvular abnormalities and the severity of diastolic dysfunction [40]. CMR is superior to echocardiography, it provides accurate assessment of ventricular volumes, wall thickness and contractile function, as well as tissue characterisation [41]. Typical patterns of subendocardial, mesocardial and subepicardial LGE distribution reflect underlying pathophysiological processes and reveal aetiology with such a level of confidence that in many cases myocardial biopsy may be omitted. CMR relaxometry can indicate myocardial necrosis, scarring, focal and diffuse replacement interstitial fibrosis, whereas high signal T2 intensity or increased T2 mapping values suggest myocardial oedema and inflammation [42]. The 4D-Flow technology allows the assessment of flowbased forces and their altered haemodynamic effects on the myocardial wall with a potential to become a maker of progressive adverse cardiac remodelling [43].

\section{Post-ischemic heart failure}

Reflecting perfusion contraction matching and mismatching, ischaemic heart failure (IHF) consists of a spectrum of pathophysiological states, from early remodelling characterised by wall thinning and dilatation to irreversible late remodelling resulting from myocardial fibrosis and scar [44]. Echocardiography with three-dimensional (3D) acquisition, in addition to stress and contrast echocardiography enables a comprehensive view of myocardial function, contractile reserve and perfusion. Resting two-dimensional echocardiograms are the first step in IHF patients and allow us to quantify $\mathrm{LV}$ function and assess the presence of resting regional wall motion abnormalities, which are the hallmark of disease [45]. Use of myocardial deformation imaging enables detection of abnormal myocardial contractility in earlier stages of the 
disease, but it is of limited value in defining aetiology or predicting viability of myocardium [46]. CMR on the other hand has a saying in myocardial viability by identifying partial or full thickness myocardial infarction based on the pattern of LGE distribution - subendocardial or transmural, respectively. Moreover, CMR showed to be superior to echocardiography in discriminating between hibernating and necrotic myocardium independently from wall thickness [47]. Akinetic segments with $>50 \%$ transmural LGE are considered nonviable (necrotic), whereas akinetic segments with no LGE have an approximately $80 \%$ likelihood of functional recovery [48]. Once the scar transmurality exceeds 50\% the likelihood of functional recovery drops to approximately $8 \%$ [49]. The presence and amount of LGE is prognostically important and associated with major adverse cardiac event (MACE) and cardiac mortality [50], and it is an independent predictor of allcause mortality or cardiac transplantation [51].

\section{Idiopathic dilated cardiomyopathy}

Mutations in over 50 genes have been associated with dilated cardiomyopathy [52]. Multiple failing mechanisms result in altered force generation and cell death, leading to left ventricular systolic dysfunction and heart failure. Diagnostic criteria of LV dilatation with reduced function applies to 'idiopathic' DCM once secondary causes have been excluded [53, 54]. Echocardiography is the first-line diagnostic tool. Volumes and $\mathrm{EF}$ acquired from 3D echocardiography correlate better with CMR and their use is recommended when feasible [55]. LV enlargement and alterations in GLS typically precedes LV dysfunction assessed by 2D classical parameters [56]. Moreover, decreased GLS showed ability to discriminate gene-positive phenotype-negative individuals from normal controls, which may permit early institution of therapy for genetic DCM [57]. Similar findings should be expected from the feature tracking obtained by CMR. CMR plays a central role in phenotypic assessment. Approximately $25 \%$ of patients with dilated cardiomyopathy (DCM) will have evidence of mid-wall fibrosis [58] which is an independent predictor of mortality and morbidity. DCM patients with mid-wall fibrosis had a similar outcome to those with ischemic disease [59]. Thus, as with ischemic cardiomyopathy, the presence of fibrosis/scar is a marker of adverse outcome and worse response to device therapy. Similarly, T1 mapping sequences together with measurement of ECV expansion has proved to have an additional value over EF in prognostic assessment (Fig. 1) [60].

\section{Systolic dysfunction in HFpEF and HFrEF patients}

The longitudinal trajectories of LV ejection fraction vary between the two conditions in a very sensitive way. When adequate follow-up is available, repeat echocardiograms in HFpEF can detect a maximum of $2-5 \%$ fell in EF over 5 years, with a larger fall in the presence of coexisting coronary artery disease [61, 62]. A similar analysis, conducted over a follow-up period up to 15 years in HFrEF patients, observed an inverted U-shaped relation whereby EF indeed increased over the initial 10 years but slowly declined afterward [63]. Comparable data should be available when looking at systolic deformation, particularly in the circumferential or radial direction, either assessed using CMR or echocardiography [64].

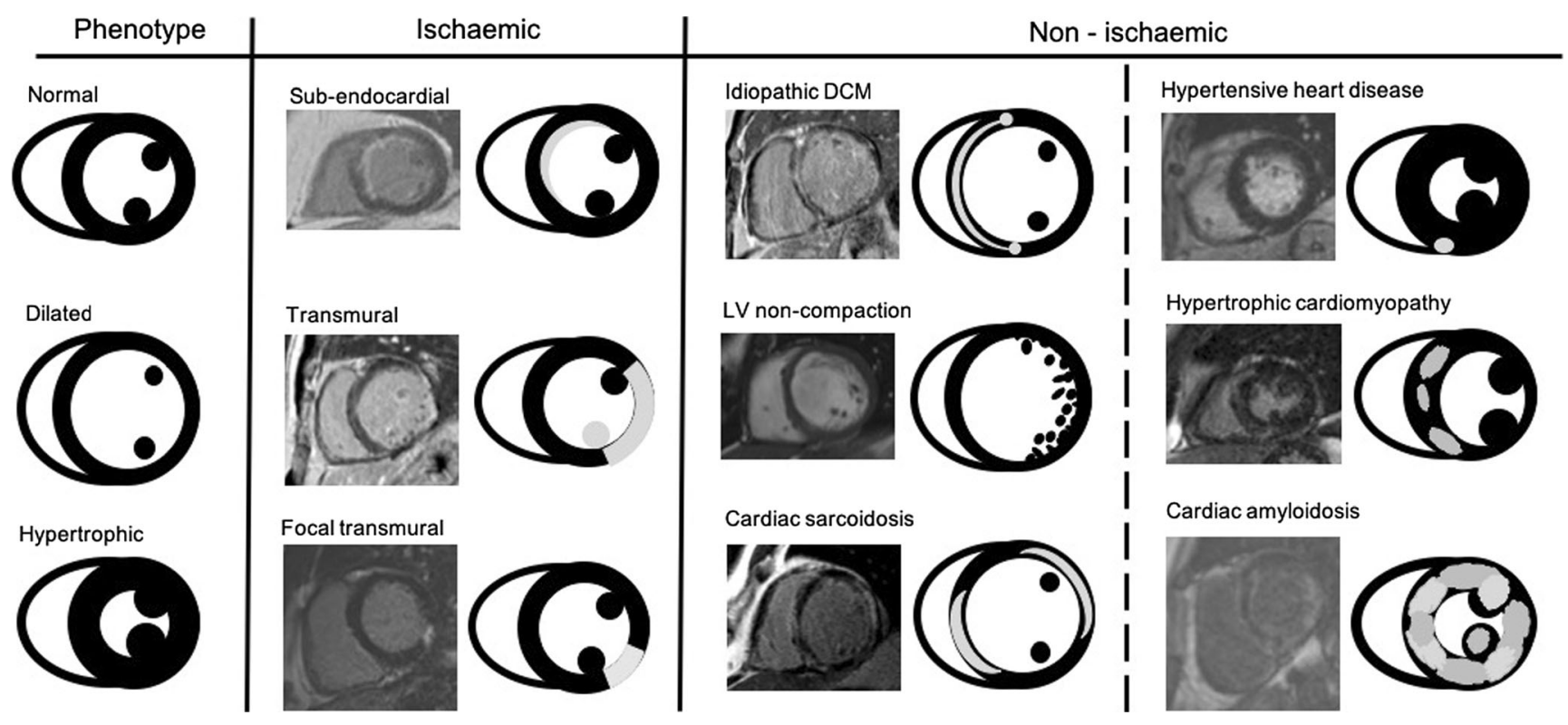

Fig. 1 Patterns of late gadolinium enhancement and corresponding cardiac MRI images 
Thus, clear discrepancies in LV systolic performance between HFpEF vs. HFrEF populations long-term trajectories make unlikely a mechanistic continuum between the two conditions, which can be represented as distinct HF phenotypes [65].

\section{Diastolic dysfunction in HFpEF and HFrEF patients}

More similarities, than discrepancies, instead, can be detected when looking at diastolic dysfunction in HFpEF vs. HFrEF patients. Diastolic dysfunction contributes to exercise intolerance, both in systolic and primary diastolic dysfunction. In both conditions, in fact, diastolic impairment limits exercise tolerance before resulting in symptoms at rest [66].

In the absence of mitral stenosis, the two major factors that determine the early diastolic mitral valve pressure gradient and the rate of LV filling are the rate of LV relaxation and the LA pressure at the time of mitral valve opening [67]. With exercise, normally, there is a fall in early diastolic LV pressure that results in an increased early diastolic pressure gradient, without an increase in LA pressure to abnormal levels. This increment in gradient, obtained with no increment in LA cavity pressure, produces an improvement in the rate of early diastolic LV filling [68]. When HF ensues, however, peak early diastolic filling rate and diastolic mitral valve pressure gradient increase as during normal exercise but with a different mechanism. Relaxation, in fact, which is slower at rest in HF, is further slowed down during exercise, while early diastolic LV pressure increases [69]. Thus, the increased rate of early diastolic LV filling and the mitral valve pressure gradient in HF result from an abnormal increase in LA pressure. Non-invasive methods to identify LV and LA pressure have recently been discussed and even the traditional echo parameters considered markers of elevated LV filling pressure such as reduced mitral deceleration time (DT) and isovolumic relaxation time (IVRT) blunted A wave and high $E / e^{\prime}$ ratio have been debated. In theory, the occurrence of the abovementioned picture is typical of a restrictive pattern and along with increased LA volume and increased pulmonary pressure, reflects high filling pressure in either HFrEF and HFpEF [70]. However, only a few studies compared Doppler and CMR parameters with direct haemodynamic measurement. Most of these studies analysed only $E / e^{\prime}$ ratio in relation to wedge pressure, but a complete measurement of left chambers pressure is lacking [71, 72]. Therefore, correlation between $E / e^{\prime}$ ratio and LVEDP in a recent metanalysis appears modest and patients with atrial fibrillation (AF) were excluded [73]. All these concerns put some doubts and limitation in evaluation of isolated diastolic dysfunction and consequently in the diagnosis of HFpEF. Thus, TDI and PW Doppler parameters may be integrated with careful analysis of cardiac structure and LV remodelling. Accordingly, elevated LA pressure leads to LA dysfunction and remodelling being commonly observed in both phenotypes. These findings, at a difference from systolic properties, would suggest a mechanistic continuum, as far as diastole is concerned, between the two conditions. It must be recognised, however, that LA remodelling in HFpEF and HFrEF, has been reported as being slightly different, with more dilation and systolic dysfunction in HFrEF and with increased stiffness, pulsatility and predilection for atrial fibrillation (AF) in HFpEF [74]. We think that this distinction is partly artefactual. The extent of LA pulsatility, that is a direct function of the stiffness of the cavity, may contribute to the pulsatile major component of right ventricular afterload [75]. Thus, from this perspective, diastolic LA dysfunction can be seen as an active contributor to symptoms and to disease progression for both phenotypes.

\section{Novel methods combining echo and CMR analysis for best risk prediction in atrial fibrillation patients}

Diastolic dysfunction is a dominant feature in many HF patients. LV diastolic dysfunction causes LA dilatation, which can lead to AF [76]. Despite of being advance in management and treatment, $\mathrm{AF}$ remains a source of considerable morbidity and mortality worldwide. For the patients in sinus rhythm LV, filling pressures and diastolic function grade can be determined reliably by a few simple echocardiographic or CMR parameters with a high feasibility [77]. However, for the patients in $\mathrm{AF}$ regardless whether $\mathrm{AF}$ is a reason or consequence, assessment of diastolic function is challenging. Assessment in this condition in limited by cycle length variability, absence on an organised atrial activity and frequent occurrence of atrial enlargement regardless of filling pressures [78]. Recently, some new indexes using speckle tracking echocardiography have shown promising results showing the association between LV systolic and diastolic strain, LA strain and LV diastolic function in AF patients [79]. Indexes potentially capable of describing the delicate atrio-ventricular relation should convey the strongest pathophysiological information and be less influenced by R-R variations, if they can be comprehensively acquired in 1 single beat.

Recently, in characterising the governing role of the fourchamber (near) constant-volume pump physiology, wherein the atrial and ventricular volumes simultaneously reciprocate throughout the cardiac cycle, CMR has elucidated and characterised LA and LV phasic function, thereby quantifying the conduit contribution to ventricular filling as the integral of net, diastolic, instantaneous difference between synchronised atrial and ventricular volume curves [80]. Because cardiac CMR availability is limited, 3D echocardiography can be employed to acquire complete and simultaneous LA and LV full-volume datasets to characterise the volume of both left- 


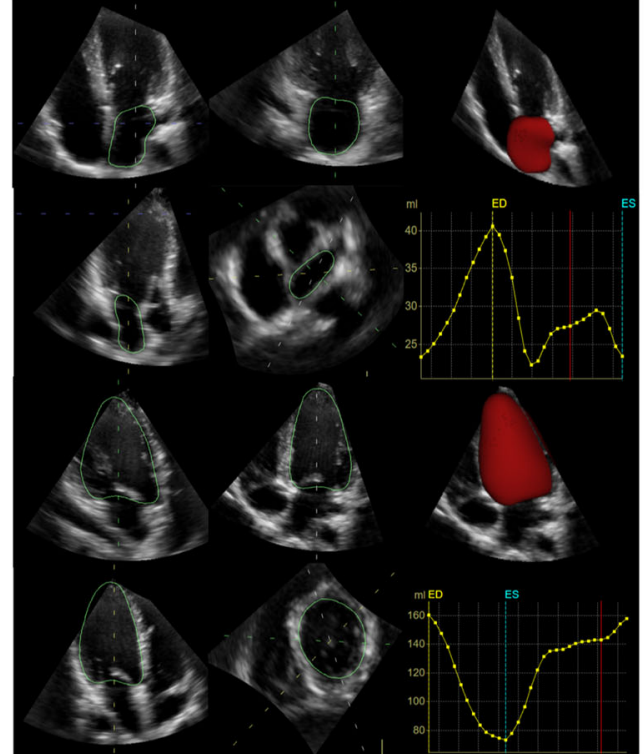

Fig. 2 Left atrial conduit volume quantification by 3D echocardiography. Left, single-beat simultaneous left atrial (LA)-left ventricular (LV) pyramidal 3D echocardiographic full-volume dataset as obtained from the apex in a given patient, using the $4 \mathrm{~V}$ transducer during held respiration (frame rate $>16.5 / \mathrm{s}$ ). The volume data are displayed in real time, three apical views and one cross-sectional slice, with optional volume-

sided cardiac chambers at each time point during the cardiac cycle in order to quantify conduit [81] (Fig. 2).

Using single-beat simultaneous left atrial and ventricular full-volume 3D dataset, it was demonstrated that the atrial conduit contribution to ventricular filling has a direct relationship with the degree of underlying ventricular diastolic impairment in HF patients [82]. More recently, it was shown that conduit quantitation is also able to predict 1-month $\mathrm{AF}$

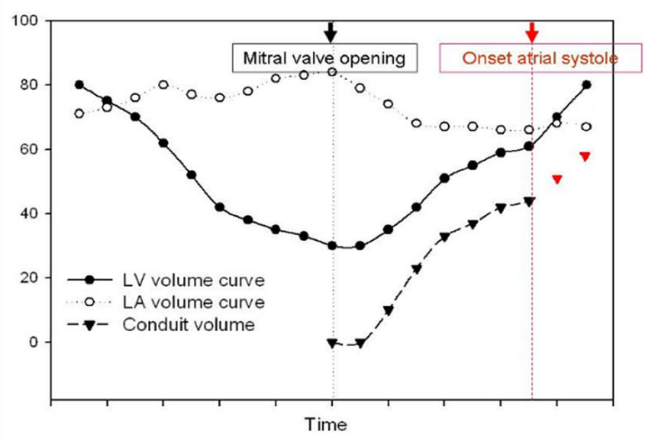

Conduit volume $(t)=[\operatorname{LV}(t)-\mathrm{LV} \min ]-[\mathrm{LA} \max -\mathrm{LA}(t)]$

rendering techniques for visualisation of valves and structures. Right, conduit volume is quantified according to the formula: (LV at time $(t)$ minus LV minimum) minus (LA maximal minus LA at time $(t)$ ), integrating volume data from minimum LV volume to the beginning of LA contraction (as identified from simultaneously acquired ECG signal) and expressed as percent of LV stroke volume

recurrence in a population of persistent AF patients imaged immediately after and/or before electrical cardioversion [83]. These findings support the concept that conduit (independently of the imaging technique used to quantify it), reflects intrinsic atrial pathology that cannot be sufficiently explained by ventricular pathology only and thus it could be proposed as a clinically effective tool for exploring the link between $\mathrm{AF}$ and diastolic dysfunction, in excess of ventricular derangement.

Fig. 3 Assessment of myocardial fibrosis by CMR. Basal, mid- and apical slices showing native $\mathrm{T} 1$ (top line) and ECV (bottom line) colour maps used for quantitative assessment of cardiac fibrosis

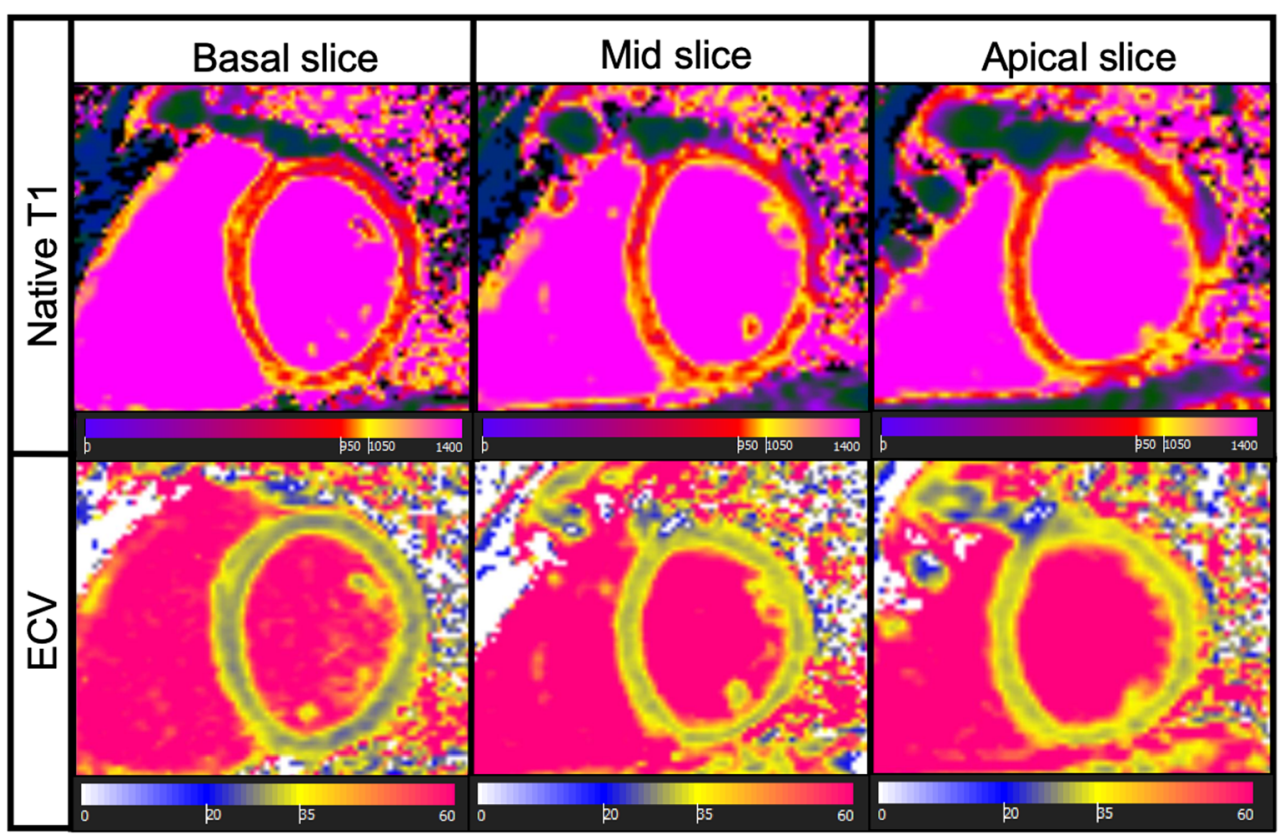


In addition to LA and LV volume curves, CMR can provide further information on myocardial tissue characteristics. Myocardial fibrosis have been implicated in the pathophysiology of HFpEF by promoting adverse ventricular remodelling, increasing myocardial stiffness, and in turn, causing diastolic dysfunction [84]. Diffuse interstitial fibrosis, a precursor for replacement fibrosis, is not detected by LGE but correlates with T1 mapping, which allows a quantitative assessment of diffuse cardiac fibrosis and estimations of the extracellular matrix volume (ECV) (Fig. 3) [85, 86]. There has been accumulating evidence that increased T1 times and ECV are related to clinical outcomes [87-89] and have potential for risk assessment in patients with AF.

\section{Conclusion}

Heart failure is disease with large phenotypic variations in morphology, function and natural history. Such a heterogeneity in presentation is perhaps a reason why despite different clustering approaches, many interventions in clinical trials have not shown efficacy. Cardiac imaging provides diverse insights, but the ability to distinguish between overlapping phenotypes remains a challenging proposition. The evaluation of diastolic function by echocardiography and CMR with their traditional and novel techniques deserves specific analysis and a comparison with haemodynamic measurement before to be universally accepted. Diastolic function parameters derived by CMR may be applied in routine clinical care and matched with more feasible echo analysis in order to increase our awareness in the HFpEF mechanisms and reduces the current diagnostic gap. New parameters studying both radial and circumferential relaxation together with identification of extracellular collagen volume could facilitate the diagnosis and will play a central role in the identification of underlying pathophysiological mechanisms. Comparative imaging trials should be encouraged in order to discern which technique(s) alone, or in combination, could provide additional prognostic value.

Acknowledgements The views expressed in this publication are those of the author(s) and not necessarily those of the NHS, the National Institute for Health Research or the Department of Health and Social Care.

Funding information CBD is in part supported by the NIHR Biomedical Research Centre at University Hospitals Bristol NHS Foundation Trust and the University of Bristol.

Open Access This article is distributed under the terms of the Creative Commons Attribution 4.0 International License (http:// creativecommons.org/licenses/by/4.0/), which permits unrestricted use, distribution, and reproduction in any medium, provided you give appropriate credit to the original author(s) and the source, provide a link to the Creative Commons license, and indicate if changes were made.

\section{References}

1. Coats AJS, Pieske B, Linde C, Jankowska EA, Ruschitzka F, Rutten FH et al (2016) ESC guidelines for the diagnosis and treatment of acute and chronic heart failure: the Task Force for the diagnosis and treatment of acute and chronic heart failure of the European Society of Cardiology (ESC) developed with the special contribution of the Heart Failure Association (HFA) of the ESC. Eur Heart J 37(27):2129-2200

2. Butler J, Fonarow GC, Zile MR, Lam CS, Roessig L, Schelbert EB et al (2014) Developing therapies for heart failure with preserved ejection fraction: current state and future directions. JACC Hear Fail 2(2):97-112

3. Ahmad T, Pencina MJ, Schulte PJ, O’Brien E, Whellan DJ, Piña IL et al (2014) Clinical implications of chronic heart failure phenotypes defined by cluster analysis. J Am Coll Cardiol 64(17): 1765-1774

4. Linzbach AJ (1960) Heart failure from the point of view of quantitative anatomy. Am J Cardiol 5:370-382

5. Grant C, Greene DG, Bunnell IL (1965) Left ventricular enlargement and hypertrophy. A clinical and angiocardiographic study. Am J Med 39(6):895-904

6. Sachdev B, Takenaka T, Teraguchi H, Tei C, Lee P, McKenna WJ, Elliott PM (2002) Prevalence of Anderson-Fabry disease in male patients with late onset hypertrophic cardiomyopathy. Circulation 105(12):1407-1411

7. Codella NCF, Lee HY, Fieno DS, Chen DW, Hurtado-Rua S, Kochar M, Finn JP, Judd R, Goyal P, Schenendorf J, Cham MD, Devereux RB, Prince M, Wang Y, Weinsaft JW (2012) Improved left ventricular mass quantification with partial voxel interpolation: in vivo and necropsy validation of a novel cardiac MRI segmentation algorithm. Circ Cardiovasc Imaging 5(1):137-146

8. Weinsaft JW, Cham MD, Janik M, Min JK, Henschke CI, Yankelevitz DF, Devereux RB (2008) Left ventricular papillary muscles and trabeculae are significant determinants of cardiac MRI volumetric measurements: effects on clinical standards in patients with advanced systolic dysfunction. Int J Cardiol 126(3): 359-365

9. Perrone-Filardi P, Coca A, Galderisi M, Paolillo S, Alpendurada F, de Simone G, Donal E, Kahan T, Mancia G, Redon J, Schmieder R, Williams B, Agabiti-Rosei E (2017) Non-invasive cardiovascular imaging for evaluating subclinical target organ damage in hypertensive patients: a consensus paper from the European Association of Cardiovascular Imaging (EACVI), the European Society of Cardiology Council on Hypertension, and the European Society of Hypertension (ESH). Eur Heart J Cardiovasc Imaging 18(9): 945-960

10. Isbell DC, Kramer CM (2005) Cardiovascular magnetic resonance: structure, function, perfusion, and viability. J Nucl Cardiol 12(3): 324-336

11. Mahrholdt H, Wagner A, Judd RM, Sechtem U, Kim RJ (2005) Delayed enhancement cardiovascular magnetic resonance assessment of non-ischaemic cardiomyopathies. Eur Heart J 26(15): $1461-1474$

12. Kannel WB, Castelli WP, McNamara PM, McKee PA, Feinleib M (1972) Role of blood pressure in the development of congestive heart failure. N Engl J Med 287(16):781-787

13. Levy D, Garrison RJ, Savage DD, Kannel WB, Castelli WP (1990) Prognostic Implications of Echocardiographically Determined Left Ventricular Mass in the Framingham Heart Study. N Engl J Med 322(22):1561-1566

14. Sehgal S, Drazner MH (2007) Left ventricular geometry: does shape matter? Am Heart J 153(2):153-155

15. Deschepper CF, Boutin-Ganache I, Zahabi A, Jiang Z (2002) In search of cardiovascular candidate genes: interactions between 
phenotypes and genotypes. Hypertens (Dallas, Tex 1979) 39(2 Pt 2):332-336

16. Grossman W, Jones D, McLaurin LP (1975) Wall stress and patterns of hypertrophy in the human left ventricle. J Clin Invest 56(1): 56-64

17. Elliott PM, Anastasakis A, Borger MA, Borggrefe M, Cecchi F, Charron P et al (2014) 2014 ESC Guidelines on diagnosis and management of hypertrophic cardiomyopathy: the Task Force for the Diagnosis and Management of Hypertrophic Cardiomyopathy of the European Society of Cardiology (ESC). Eur Heart J England 35(39):2733-2779

18. Bursi F, Weston SA, Redfield MM, Jacobsen SJ, Pakhomov S, Nkomo VT, Meverden RA, Roger VL (2006) Systolic and Diastolic Heart Failure in the Community. JAMA 296(18):22092216

19. Lang RM, Badano LP, Mor-Avi V, Afilalo J, Armstrong A, Ernande L et al (2015) Recommendations for cardiac chamber quantification by echocardiography in adults: an update from the American Society of Echocardiography and the European Association of Cardiovascular Imaging. J Am Soc Echocardiogr 28(1):1-39.e14

20. Bacharova L, Chen H, Estes EH, Mateasik A, Bluemke DA, Lima JAC, Burke GL, Soliman EZ (2015) Determinants of discrepancies in detection and comparison of the prognostic significance of left ventricular hypertrophy by electrocardiogram and cardiac magnetic resonance imaging. Am J Cardiol 115(4):515-522

21. Pagourelias ED, Mirea O, Duchenne J, Van Cleemput J, Delforge M, Bogaert J et al (2017) Echo parameters for differential diagnosis in cardiac amyloidosis: a head-to-head comparison of deformation and nondeformation parameters. Circ Cardiovasc Imaging 10(3): $\mathrm{e} 005588$

22. Afonso L, Kondur A, Simegn M, Niraj A, Hari P, Kaur R et al (2012) Two-dimensional strain profiles in patients with physiological and pathological hypertrophy and preserved left ventricular systolic function: a comparative analyses. BMJ Open 2(4)

23. Rocio H, Niharika V, Nick C, Benjamin G, Andrew J, Chung-Yao Y et al (2015) T1 mapping in discrimination of hypertrophic phenotypes: hypertensive heart disease and hypertrophic cardiomyopathy. Circ Cardiovasc Imaging 8(12):e003285

24. Rodrigues JC, Rohan S, Dastidar AG, Burchell AE, Ratcliffe LE, Hart EC et al (2016) Hypertensive heart disease versus hypertrophic cardiomyopathy: multi-parametric CMR predictors beyond enddiastolic wall thickness $\geq 15 \mathrm{~mm}$. J Cardiovasc Magn Reson 18(1): P264

25. Devereux RB, Alderman MH (1993) Role of preclinical cardiovascular disease in the evolution from risk factor exposure to development of morbid events. Circulation 88(4 Pt 1):1444-1455

26. Mancia G, Fagard R, Narkiewicz K, Redon J, Zanchetti A, Bohm $\mathrm{M}$ et al (2013) $2013 \mathrm{ESH} / \mathrm{ESC}$ guidelines for the management of arterial hypertension: the Task Force for the Management of Arterial Hypertension of the European Society of Hypertension (ESH) and of the European Society of Cardiology (ESC). Eur Heart J 34(28):2159-2219

27. Lancellotti P, Galderisi M, Edvardsen T, Donal E, Goliasch G, Cardim N, Magne J, Laginha S, Hagendorff A, Haland TF, Aaberge L, Martinez C, Rapacciuolo A, Santoro C, Ilardi F, Postolache A, Dulgheru R, Mateescu AD, Beladan CC, Deleanu D, Marchetta S, Auffret V, Schwammenthal E, Habib G, Popescu BA (2017) Echo-Doppler estimation of left ventricular filling pressure: results of the multicentre EACVI Euro-Filling study. Eur Heart J Cardiovasc Imaging 18(9):961-968

28. Tabata T, Thomas JD, Klein AL (2003) Pulmonary venous flow by doppler echocardiography: revisited 12 years later. J Am Coll Cardiol 41(8): 1243-1250

29. Chamsi-Pasha MA, Zhan Y, Debs D, Shah DJ (2019) CMR in the evaluation of Diastolic Dysfunction and Phenotyping of HFpEF: current role and future perspectives. JACC Cardiovasc Imaging
30. Falk RH (2005 Sep) Diagnosis and management of the cardiac amyloidoses. Circulation United States 112(13):2047-2060

31. Pozo E, Kanwar A, Deochand R, Castellano JM, Naib T, PazosLopez P et al (2014) Cardiac magnetic resonance evaluation of left ventricular remodelling distribution in cardiac amyloidosis. Heart 100(21):1688-1695

32. Pewsner D, Battaglia M, Minder C, Marx A, Bucher HC, Egger M (2004) Ruling a diagnosis in or out with "SpPIn" and "SnNOut": a note of caution. BMJ 329(7459):209-213

33. Phelan D, Collier P, Thavendiranathan P, Popovic ZB, Hanna M, Plana JC et al (2012) Relative apical sparing of longitudinal strain using two-dimensional speckle-tracking echocardiography is both sensitive and specific for the diagnosis of cardiac amyloidosis. Heart 98(19): 1442-1448

34. Bellavia D, Pellikka PA, Abraham TP, Al-Zahrani GB, Dispenzieri A, Oh JK et al (2008) Evidence of impaired left ventricular systolic function by Doppler myocardial imaging in patients with systemic amyloidosis and no evidence of cardiac involvement by standard two-dimensional and Doppler echocardiography. Am J Cardiol 101(7):1039-1045

35. Innelli $\mathrm{P}$, Galderisi $\mathrm{M}$, Catalano L, Martorelli MC, Olibet M, Pardo $\mathrm{M}$ et al (2006) Detection of increased left ventricular filling pressure by pulsed tissue Doppler in cardiac amyloidosis. J Cardiovasc Med (Hagerstown) 7(10):742-747

36. Liu D, Hu K, Niemann M, Herrmann S, Cikes M, Stork S et al (2013) Effect of combined systolic and diastolic functional parameter assessment for differentiation of cardiac amyloidosis from other causes of concentric left ventricular hypertrophy. Circ Cardiovasc Imaging 6(6): 1066-1072

37. Karamitsos TD, Piechnik SK, Banypersad SM, Fontana M, Ntusi NB, Ferreira VM, Whelan CJ, Myerson SG, Robson MD, Hawkins PN, Neubauer S, Moon JC (2013) Noncontrast T1 mapping for the diagnosis of cardiac amyloidosis. JACC Cardiovasc Imaging 6(4): 488-497

38. Ferreira VM, Schulz-Menger J, Holmvang G, Kramer CM, Carbone I, Sechtem U, Kindermann I, Gutberlet M, Cooper LT, Liu P, Friedrich MG (2018) Cardiovascular magnetic resonance in nonischemic myocardial inflammation: expert recommendations. J Am Coll Cardiol 72(24):3158-3176

39. Gaasch WH, Meyer TE (2008) Left ventricular response to mitral regurgitation: implications for management. Circulation 118(22): 2298-2303

40. Rihal CS, Nishimura RA, Hatle LK, Bailey KR, Tajik AJ (1994) Systolic and diastolic dysfunction in patients with clinical diagnosis of dilated cardiomyopathy. Relation to symptoms and prognosis. Circulation 90(6):2772-2779

41. Moon JC, Messroghli DR, Kellman P, Piechnik SK, Robson MD, Ugander M et al (2013) Myocardial T1 mapping and extracellular volume quantification: a Society for Cardiovascular Magnetic Resonance (SCMR) and CMR Working Group of the European Society of Cardiology consensus statement. J Cardiovasc Magn Reson 15:92

42. Friedrich MG, Sechtem U, Schulz-Menger J, Holmvang G, Alakija P, Cooper LT, White JA, Abdel-Aty H, Gutberlet M, Prasad S, Aletras A, Laissy JP, Paterson I, Filipchuk NG, Kumar A, Pauschinger M, Liu P, International Consensus Group on Cardiovascular Magnetic Resonance in Myocarditis (2009) Cardiovascular magnetic resonance in myocarditis: a JACC White Paper. J Am Coll Cardiol 53(17):1475-1487

43. Eriksson J, Bolger AF, Ebbers T, Carlhäll C-J (2016) Assessment of left ventricular hemodynamic forces in healthy subjects and patients with dilated cardiomyopathy using 4D flow MRI. Phys Rep 4(3): e12685

44. Gerd H (2013) The regional myocardial flow-function relationship. Circ Res 112(12):1535-1537 
45. Nihoyannopoulos P, Vanoverschelde JL (2011) Myocardial ischaemia and viability: the pivotal role of echocardiography. Eur Heart J 32(7):810-819

46. Tarascio M, Leo LA, Klersy C, Murzilli R, Moccetti T, Faletra FF (2017) Speckle-tracking layer-specific analysis of myocardial deformation and evaluation of scar transmurality in chronic ischemic heart disease. J Am Soc Echocardiogr 30(7):667-675

47. La Canna G, Rahimtoola SH, Visioli O, Giubbini R, Alfieri O, Zognio M et al (2000) Sensitivity, specificity, and predictive accuracies of non-invasive tests, singly and in combination, for diagnosis of hibernating myocardium. Eur Heart J 21(16):1358-1367

48. Selvanayagam JB, Kardos A, Francis JM, Wiesmann F, Petersen SE, Taggart DP, Neubauer S (2004) Value of delayed-enhancement cardiovascular magnetic resonance imaging in predicting myocardial viability after surgical revascularization. Circulation 110(12): $1535-1541$

49. Kim RJ, Wu E, Rafael A, Chen EL, Parker MA, Simonetti O, Klocke FJ, Bonow RO, Judd RM (2000) The use of contrastenhanced magnetic resonance imaging to identify reversible myocardial dysfunction. N Engl J Med 343(20):1445-1453

50. Kwong RY, Chan AK, Brown KA, Chan CW, Reynolds HG, Tsang S, Davis RB (2006) Impact of unrecognized myocardial scar detected by cardiac magnetic resonance imaging on event-free survival in patients presenting with signs or symptoms of coronary artery disease. Circulation 113(23):2733-2743

51. Cheong BYC, Muthupillai R, Wilson JM, Sung A, Huber S, Amin S, Elayda MA, Lee VV, Flamm SD (2009) Prognostic significance of delayed-enhancement magnetic resonance imaging: survival of 857 patients with and without left ventricular dysfunction. Circulation 120(21):2069-2076

52. McNally EM, Golbus JR, Puckelwartz MJ (2013) Genetic mutations and mechanisms in dilated cardiomyopathy. J Clin Invest 123(1):19-26

53. Henry WL, Gardin JM, Ware JH (1980) Echocardiographic measurements in normal subjects from infancy to old age. Circulation 62(5):1054-1061

54. Mestroni L, Maisch B, McKenna WJ, Schwartz K, Charron P, Rocco C, Tesson F, Richter A, Wilke A, Komajda M (1999) Guidelines for the study of familial dilated cardiomyopathies. Collaborative Research Group of the European Human and Capital Mobility Project on Familial Dilated Cardiomyopathy. Eur Heart J 20(2):93-102

55. Ruddox V, Mathisen M, Baekkevar M, Aune E, Edvardsen T, Otterstad JE (2013) Is 3D echocardiography superior to 2D echocardiography in general practice? A systematic review of studies published between 2007 and 2012. Int J Cardiol 168(2):1306-1315

56. Fatkin D, Yeoh T, Hayward CS, Benson V, Sheu A, Richmond Z, Feneley MP, Keogh AM, Macdonald PS (2011) Evaluation of left ventricular enlargement as a marker of early disease in familial dilated cardiomyopathy. Circ Cardiovasc Genet 4(4):342-348

57. van der Bijl P, Bootsma M, Hiemstra YL, Ajmone Marsan N, Bax JJ, Delgado V (2019) Left ventricular 2D speckle tracking echocardiography for detection of systolic dysfunction in genetic, dilated cardiomyopathies. Eur Heart J Cardiovasc Imaging 20(6):694-699

58. McCrohon JA, Moon JCC, Prasad SK, McKenna WJ, Lorenz CH, Coats AJS et al (2003) Differentiation of heart failure related to dilated cardiomyopathy and coronary artery disease using gadolinium-enhanced cardiovascular magnetic resonance. Circulation 108(1):54-59

59. Leyva F, Taylor RJ, Foley PWX, Umar F, Mulligan LJ, Patel K, Stegemann B, Haddad T, Smith RE, Prasad SK (2012) Left ventricular midwall fibrosis as a predictor of mortality and morbidity after cardiac resynchronization therapy in patients with nonischemic cardiomyopathy. J Am Coll Cardiol 60(17):1659-1667

60. Luetkens JA, Homsi R, Sprinkart AM, Doerner J, Dabir D, Kuetting DL, Block W, Andrié R, Stehning C, Fimmers R,
Gieseke J, Thomas DK, Schild HH, Naehle CP (2016) Incremental value of quantitative CMR including parametric mapping for the diagnosis of acute myocarditis. Eur Heart J Cardiovasc Imaging 17(2):154-161

61. Dunlay SM, Roger VL, Weston SA, Jiang R, Redfield MM (2012) Longitudinal changes in ejection fraction in heart failure patients with preserved and reduced ejection fraction. Circ Heart Fail 5(6): 720-726

62. Lupon J, Gavidia-Bovadilla G, Ferrer E, de Antonio M, PereraLluna A, Lopez-Ayerbe J et al (2019) Heart failure with preserved ejection fraction infrequently evolves toward a reduced phenotype in long-term survivors. Circ Heart Fail 12(3):e005652

63. Lupon J, Gavidia-Bovadilla G, Ferrer E, de Antonio M, PereraLluna A, Lopez-Ayerbe J et al (2018) Dynamic trajectories of left ventricular ejection fraction in heart failure. J Am Coll Cardiol 72(6):591-601

64. van Everdingen WM, Zweerink A, Nijveldt R, Salden OAE, Meine M, Maass AH, Vernooy K, de Lange FJ, van Rossum A, Croisille P, Clarysse P, Geelhoed B, Rienstra M, van Gelder I, Vos MA, Allaart CP, Cramer MJ (2018) Comparison of strain imaging techniques in CRT candidates: CMR tagging, CMR feature tracking and speckle tracking echocardiography. Int J Card Imaging 34(3):443-456

65. Paulus WJ (2019) Phenotypic persistence in heart failure with preserved ejection fraction. Circulation:e005956

66. Little WC, Kitzman DW, Cheng CP (2000) Diastolic dysfunction as a cause of exercise intolerance. Heart Fail Rev 5(4):301-306

67. Ishida Y, Meisner JS, Tsujioka K, Gallo JI, Yoran C, Frater RW, Yellin EL (1986) Left ventricular filling dynamics: influence of left ventricular relaxation and left atrial pressure. Circulation 74(1): 187-196

68. Cheng CP, Freeman GL, Santamore WP, Constantinescu MS, Little WC (1990) Effect of loading conditions, contractile state, and heart rate on early diastolic left ventricular filling in conscious dogs. Circ Res 66(3):814-823

69. Sato H, Hori M, Ozaki H, Yokoyama H, Imai K, Morikawa M et al (1993) Exercise-induced upward shift of diastolic left ventricular pressure-volume relation in patients with dilated cardiomyopathy. Effects of beta-adrenoceptor blockade. Circulation 88(5 Pt 1): 2215-2223

70. Flachskampf FA, Biering-Sørensen T, Solomon SD, Duvernoy O, Bjerner T, Smiseth OA (2015) Cardiac imaging to evaluate left ventricular diastolic function. JACC Cardiovasc Imaging 8(9): 1071-1093

71. Michaud M, Maurin V, Simon M, Chauvel C, Bogino E, Abergel E (2019) Patients with high left ventricular filling pressure may be missed applying 2016 echo guidelines: a pilot study. Int J Card Imaging (in press)

72. Hummel YM, Liu LCY, Lam CSP, Fonseca-Munoz DF, Damman K, Rienstra M, van der Meer P, Rosenkranz S, van Veldhuisen D, Voors AA, Hoendermis ES (2017) Echocardiographic estimation of left ventricular and pulmonary pressures in patients with heart failure and preserved ejection fraction: a study utilizing simultaneous echocardiography and invasive measurements. Eur J Heart Fail 19(12):1651-1660

73. Nauta JF, Hummel YM, van der Meer P, Lam CSP, Voors AA, van Melle JP (2018) Correlation with invasive left ventricular filling pressures and prognostic relevance of the echocardiographic diastolic parameters used in the 2016 ESC heart failure guidelines and in the 2016 ASE/EACVI recommendations: a systematic review in patients with heart failure with preserved ejection fraction. Eur J Heart Fail 20(9):1303-1311

74. Suga H (1974) Importance of atrial compliance in cardiac performance. Circ Res 35(1):39-43

75. Tedford RJ (2014) Determinants of right ventricular afterload (2013 Grover Conference series). Pulm Circ 4(2):211-219 
76. Tsang TSM, Gersh BJ, Appleton CP, Tajik AJ, Barnes ME, Bailey KR, Oh JK, Leibson C, Montgomery SC, Seward JB (2002) Left ventricular diastolic dysfunction as a predictor of the first diagnosed nonvalvular atrial fibrillation in 840 elderly men and women. J Am Coll Cardiol 40(9):1636-1644

77. Nacif MS, Almeida ALC, Young AA, Cowan BR, Armstrong AC, Yang E, Sibley CT, Hundley WG, Liu S, Lima JA, Bluemke DA (2017) Three-dimensional volumetric assessment of diastolic function by cardiac magnetic resonance imaging: the Multi-Ethnic Study of Atherosclerosis (MESA). Arq Bras Cardiol 108(6):552563

78. Nagueh SF, Kopelen HA, Quiñones MA (1996) Assessment of left ventricular filling pressures by Doppler in the presence of atrial fibrillation. Circulation 94(9):2138-2145

79. Dokainish H, Sengupta R, Pillai M, Bobek J, Lakkis N (2008) Usefulness of new diastolic strain and strain rate indexes for the estimation of left ventricular filling pressure. Am J Cardiol 101(10): 1504-1509

80. Bowman AW, Kovacs SJ (2004) Left atrial conduit volume is generated by deviation from the constant-volume state of the left heart: a combined MRI-echocardiographic study. Am J Physiol Heart Circ Physiol 286(6):H2416-H2424

81. Nappo R, Degiovanni A, Bolzani V, Sartori C, Di Giovine G, Cerini $P$ et al (2016) Quantitative assessment of atrial conduit function: a new index of diastolic dysfunction. Clin Res Cardiol 105(1):17-28

82. Degiovanni A, Boggio E, Prenna E, Sartori C, De Vecchi F, Marino PN (2018) Association between left atrial phasic conduit function and early atrial fibrillation recurrence in patients undergoing electrical cardioversion. Clin Res Cardiol 107(4):329-337

83. Giubertoni A, Boggio E, Ubertini E, Zanaboni J, Calcaterra E, Degiovanni A et al (2019) Atrial conduit function quantitation precardioversion predicts early arrhythmia recurrence in persistent atrial fibrillation patients. J Cardiovasc Med (Hagerstown) 20(4): 169-179
84. Mewton N, Liu CY, Croisille P, Bluemke D, Lima JAC (2011) Assessment of myocardial fibrosis with cardiovascular magnetic resonance. J Am Coll Cardiol 57(8):891-903

85. Iles L, Pfluger H, Phrommintikul A, Cherayath J, Aksit P, Gupta SN, Kaye DM, Taylor AJ (2008) Evaluation of diffuse myocardial fibrosis in heart failure with cardiac magnetic resonance contrastenhanced T1 mapping. J Am Coll Cardiol 52(19):1574-1580

86. Flett AS, Hayward MP, Ashworth MT, Hansen MS, Taylor AM, Elliott PM, McGregor C, Moon JC (2010) Equilibrium contrast cardiovascular magnetic resonance for the measurement of diffuse myocardial fibrosis. Circulation 122(2):138-144

87. Roy C, Slimani A, de Meester C, Amzulescu M, Pasquet A, Vancraeynest D, Beauloye C, Vanoverschelde JL, Gerber BL, Pouleur AC (2018) Associations and prognostic significance of diffuse myocardial fibrosis by cardiovascular magnetic resonance in heart failure with preserved ejection fraction. J Cardiovasc Magn Reson 20(1):55

88. Schelbert EB, Fridman Y, Wong TC, Abu Daya H, Piehler KM, Kadakkal A, Miller CA, Ugander M, Maanja M, Kellman P, Shah DJ, Abebe KZ, Simon MA, Quarta G, Senni M, Butler J, Diez J, Redfield MM, Gheorghiade M (2017) Temporal relation between myocardial fibrosis and heart failure with preserved ejection fraction: association with baseline disease severity and subsequent outcome. JAMA Cardiol 2(9):995-1006

89. Webb J, Fovargue L, Tondel K, Porter B, Sieniewicz B, Gould J et al (2018) The emerging role of cardiac magnetic resonance imaging in the evaluation of patients with HFpEF. Curr Heart Fail Rep 15(1):1-9

Publisher's note Springer Nature remains neutral with regard to jurisdictional claims in published maps and institutional affiliations. 